\title{
Climate and aeroallergen levels in asthma: a 12 month prospective study
}

\author{
Michael J Epton, Isobel R Martin, Patrick Graham, Patricia E Healy, Heather Smith, \\ Rengasamy Balasubramaniam, Ian C Harvey, David W Fountain, John Hedley, \\ G Ian Town
}

Abstract

Background - There is evidence to suggest that changes in weather and airborne fungal spore and pollen counts may affect asthma symptoms. Methods - The relationship between climate, airborne fungal spore, and pollen counts and peak expiratory flow rate (PEFR) and asthma symptoms was prospectively investigated in a population of mild to moderate asthmatic subjects in Blenheim, New Zealand. Subjects recorded twice daily PEFR measurements and asthma symptom scores for up to one year. Spore and pollen counts were measured two hourly and meteorological data were measured hourly. Individual, within person, multiple linear regression analyses were conducted, adjusting for autocorrelation. A random effects model was assumed for the individual regression coefficients and weighted estimates of the mean of these coefficients were obtained by the method of maximum likelihood.

Results - One hundred and thirty nine asthmatic patients (60\% atopic) aged $17-80$ years completed the study. Of the weather variables, only temperature showed a small but consistent association with PEFR. The mean rise in $\mathrm{PEFR}$ for an $8.8^{\circ} \mathrm{C}$ (2 SD) change in temperature was $0.78 \%$ (95\% CI $0.44 \%$ to $1.11 \%)$, approximately $3.01 / \mathrm{min}$. There was a weak association between days of high basidiospore counts and increased nocturnal wakening and reliever medication use. Pollen counts showed no consistent association with either PEFR or asthma symptoms. Conclusions - The results of this study suggest that the effects of weather and aeroallergens on PEFR and asthma symptoms in this population are small, and that other causes need to be sought to account for variations in asthma severity and exacerbations.

(Thorax 1997;52:528-534)

Keywords: asthma, aeroallergen, climate, fungal spores.

New Zealan

D W Fountain

Correspondence to:

Dr G I Town, Christchurch School of Medicine, PO Box 4345, Christchurch, New Zealand.

Received 28 August 1996 Returned to authors 23 October 1996

Revised version received

21 January 1997

Accepted for publication

12 February 1997

There is some evidence to suggest that climatic changes and variation in the levels of airborne allergens may be responsible for fluctuations in asthma symptoms. ${ }^{1-5}$ Epidemics of acute asthma have been described at the time of dramatic meteorological events such as thunderstorms. ${ }^{6-9}$ Similarly, massive aeroallergen concentrations such as occurred in Barcelona in relation to soya bean dust have been associated with large numbers of acute exacerbations. ${ }^{10}$

Inhaled pollens are an established cause of respiratory symptoms in humans. In New Zealand introduced species such as grasses, birch, macrocarpa, oak, alder, pine, wattle and plantain are among the commonly described aeroallergens. ${ }^{112}$ Some studies have linked increased pollen levels to asthma admissions and others have associated pollen exposure with increased bronchial responsiveness. ${ }^{13-17} \mathrm{~A}$ variety of fungal spores including ascospores, basidiospores, and airborne spores of species of Cladosporium and Alternaria have been implicated as trigger factors in asthmatic subjects. ${ }^{1819}$

Most previous studies designed to examine possible relationships between weather, aeroallergens, and asthma have relied on asthma admissions or visits to the emergency department as outcome measures. Few prospective studies have been reported on the effects of weather and aeroallergens on peak flow and asthma symptoms and these studies have been only of short duration. ${ }^{2021}$

A prospective study was performed to explore relationships between weather, fungal spore counts, pollen counts and peak expiratory flow rates (PEFR) and asthma symptoms in a group of subjects with asthma. The study was performed in Blenheim, a small rural town in the South Island of New Zealand (population 20000 ), and lasted for one year from 1 July 1992 to 30 June 1993.

\section{Methods}

SUBJECTS

Subjects were recruited by a media campaign and through contact with local medical practitioners. At a screening clinic a respiratory questionnaire was administered and skin prick testing performed with common allergens. Subjects with chronic obstructive pulmonary disease as their primary diagnosis were excluded during screening. Following recruitment, the subjects' general practitioners were contacted to confirm that a diagnosis of asthma had been made according to American Thoracic Society criteria. $^{22}$ All subjects but one lived within
$19 \mathrm{~km}$ of the spore and pollen monitoring site.

DAILY ASTHMA RECORDINGS

Subjects were issued with diary cards and a mini-Wright peak flow meter and instructed on 
their use. They were asked to record twice daily (best of three before medication) PEFR, use of reliever medication, nocturnal wakening, and asthma symptom score on a standard four point scale. Subjects were requested not to record data on days when they were away from the area for the whole day.

EXACERBATIONS OF ASTHMA

Severe exacerbations requiring attendance at either the general practitioner's surgery or emergency department for nebuliser treatment were also noted on the diary card.

WEATHER RECORDINGS

Temperature, relative humidity, and rainfall were measured hourly at the monitoring site situated due north on the outskirts of the town, and barometric pressure was measured at the local airfield.

SPORE AND POLLEN DATA

Spore and pollen data were collected two hourly using a single Burkard spore trap. Airborne particles passed through an aperture and were deposited on the surface of a sticky $3 \mathrm{M}$ Mylar tape. The tape was attached to a rotating drum which moved at $2 \mathrm{~mm} / \mathrm{h}$, completing a single revolution every seven days. At the end of each seven day cycle the tape was removed, attached to glass slides, stained with trypan blue, and examined microscopically.

Aerospores were counted by randomly selecting a field under the microscope on a portion of the tape corresponding to a two hourly interval. Spore identification to species level was not attempted because of the accepted morphological similarities between many fungal species and genera. For the analyses reported here, all spores were classified as ascospores, basidiospores, or conidia. Pollen identified included pine (chiefly Pinus radiata), macrocarpa, wattle, oak, alder, birch, plantain, and grasses. Other pollen seen were grouped as "other deciduous trees", weeds, and "unidentified".

The study was approved by the ethics committees of the then Nelson/Marlborough Area and Wellington Area Health Authorities. Written informed consent to participate was obtained from each subject.

STATISTICAL ANALYSIS

Outcome variables

The outcome data were drawn from the daily diaries and included morning and evening PEFR, asthma symptom score, reliever medication use, and nocturnal wakening. PEFR data were logarithmically transformed to provide appropriate regression models. The symptom score variable was dichotomised by defining any day on which an individual recorded a score greater than their modal score as a high score day. All other days were classed as normal with respect to symptom score. The modal score accounted for at least $50 \%$ of days in most individuals. Similarly, the reliever medication data were dichotomised as high or normal, with the cut off point being set at two doses greater than the category containing the individual's median usage. The first 14 days of each participant's diary data were excluded from analysis to overcome any training effects.

Predictor variables

The predictor or explanatory variables were the climatic variables and aeroallergen levels. The climatic variables used in the regression analyses were mean daily temperature, mean daily barometric pressure, mean daily relative humidity, mean daily rainfall and, for each day, the maximum fall in barometric pressure observed during a two hour period. The last variable was intended to capture the effect of a sudden fall in barometric pressure. Information on wind run and wind direction was not used for the analyses since these data were available for only 265 of the 365 days of the study period.

From the two hourly spore and pollen counts mean daily densities per $\mathrm{m}^{3}$ of air were calculated for each 24 hour period. The spore data were classified into three major spore types: ascospores, basidiospores, and conidia. For each spore category each day was designated as a high, moderate, or low day. This classification used the following cut off points: $>66$ th percentile, 33-66th percentiles, and <33rd percentile. For total pollen a standard classification was employed with cut off points at 10 grains/ $\mathrm{m}^{3}$ and 100 grains $/ \mathrm{m}^{3}$. There were no days with a pollen count in excess of 100 grains $/ \mathrm{m}^{3}$ so comparisons refer to the effect of moderate compared with low pollen days. Using the above classifications, spore and pollen levels were represented by dummy variables (two for each spore type and one for total pollen) in the regression analyses. In each case the category representing the lowest level was used as the reference category. The spore and pollen levels were treated as categorical variables because, particularly in the case of spores, the range of observed levels was very large and linearity assumptions seemed inappropriate.

In order to allow for the possibility of linear drift in study outcomes over the study period we included day of the study (1-351) in the regression models. In order to allow for some additional flexibility in the modelling of long term time effects we also included the square of the day of study in the regression models that is, a quadratic function of time was included. More complex modelling of time effects was not undertaken because exploratory analyses were not suggestive of complex long term time effects such as cyclic patterns. Such patterns are probably less likely in a single year study such as ours than in multi year studies in which regular seasonal effects would be anticipated.

Regression analyses for the PEFR data

In order to allow for the possibility of heterogeneity between participants we used random coefficients linear regression models for analysis 
of the relationship of PEFR data to the explanatory variables. ${ }^{23-25}$ This involved a two stage modelling process. Firstly, linear regression analyses were conducted for each individual, adjusting for first order autocorrelation via a two-step Cochrane-Orcutt method. ${ }^{26}$ The second stage of the random coefficients regression model assumed that, for each variable, the distribution of the collection of individual parameter estimates could be approximated by a normal distribution. The focus of the second stage of the analysis was on estimating the mean and variance of this distribution by maximum likelihood methods. The resulting estimate of the mean is a weighted average of the individual estimates, with the weights inversely proportional to the estimated variances of the individual estimates.

The assumptions of normality which underpin the random coefficients regression models were checked by inspecting weighted normal plots. ${ }^{27}$ These plots indicated that the observed distributions for several of the parameter estimates tended to be slightly short tailed - that is, there were fewer data than expected in the extremes of the distribution. The implication of this is that the standard errors, confidence intervals, and $\mathrm{p}$ values for the PEFR analyses reported may be slightly conservative.

Since PEFR data were logarithmically transformed prior to analysis, exponentiating individual parameter estimates gives an estimate of the multiplicative change in outcome (PEFR) due to a one unit change in the predictor variable. Exponentiating the mean of the individual parameter estimates gives the geometric mean of the individual multiplicative changes and this is expressed below as a percentage change in PEFR. Confidence intervals for the geometric mean percentage change were computed as geometric mean percentage change $\times \exp ( \pm 1.96 \times$ standard error $)$.

Regression analyses for symptom score, nocturnal wakening, and use of reliever medication

For each of these variables, the analysis focused on incident occurrences of the symptom in question (high symptom score, nocturnal wakening, or high reliever medication use). An incident occurrence of a particular symptom was defined as the reporting of the symptom of interest by an individual who had been free of the symptom the previous day. This approach was taken both because it seemed more appropriate in terms of the study hypotheses and reduced autocorrelation.

For these dichotomous outcome variables it proved possible to fit individual logistic regression models in only about $50 \%$ of cases. Consequently, possible inter-individual heterogeneity was accounted for by grouping individuals according to their age (younger or older than 50 years), smoking history (ever or never smoker), and atopic status and conducting separate analyses for each group rather than for each individual. The resulting groupspecific estimates were then analysed via a random effects model similar to that employed in the second stage of the PEFR analyses. The residual first order autocorrelation for the group specific analyses ranged from -0.20 to 0.02 , providing little evidence of autocorrelation.

In order to estimate the group-specific relative risks we maximised a Poisson likelihood function for the dependence of symptom incidence (computed as number of incident events/number of eligibles responding who were free of the symptom of interest on the previous day) on climatic and aeroallergen variables. This model yields consistent relative risk estimates even when the outcome data are not Poisson distributed. ${ }^{28}$ However, since the usual model based variance estimates are inappropriate when, as is likely to be the case here, the data are not Poisson distributed, a model robust method was employed to estimate the variance of the parameter estimates. ${ }^{29}$

Exponentiating the (weighted) mean of the group-specific parameter estimates yields an estimate of the geometric mean of the groupspecific relative risks. It is this geometric mean relative risk which is reported below, together with $95 \%$ confidence intervals computed as geometric mean relative risk $\times \exp ( \pm 1.96 \times$ standard error).

\section{Software}

The SAS procedures Reg and Logist ${ }^{3031}$ were used for the first stage linear and Poisson regression analyses. Programs implementing the second stage random effects models and the weighted normal plots were written using the Gauss matrix language. ${ }^{32}$

Power of the study

Based on the observed standard errors, the PEFR analyses had power greater than $95 \%$ to detect a 5\% change in PEFR, in association with a $2 S D$ change in climatic variables or a change from low to moderate or low to high aeroallergen levels.

For the daytime symptom score, nocturnal wakening, and use of reliever medication the study had power greater than $90 \%$ to detect rate ratios of $1.4,1.7$, and 1.5 , respectively, in association with a $2 \mathrm{SD}$ change in climatic variables or a change from low to moderate or low to high aeroallergen levels.

Interpretation of results

In order to aid the interpretation of the results of the regression analyses the results reported have been standardised so that, for each climatic variable, the reported effect corresponds to the effect of a $2 \mathrm{SD}$ change in that variable. For the aeroallergen levels the reported effects correspond to the effect of a change from low to moderate or low to high aeroallergen levels - that is, days with low aeroallergen levels form the reference group.

\section{Results}

\section{COHORT DETAILS}

A total of 205 people were screened and 139 were entered into the study. Reasons for ex- 
Table 1 Demographic and baseline characteristics $(n=139)$

\begin{tabular}{|c|c|c|}
\hline Mean (range) age (years) & 49 & $(17-80)$ \\
\hline \multicolumn{3}{|l|}{ Sex } \\
\hline Men & 47 & $(34 \%)$ \\
\hline Women & 92 & $(66 \%)$ \\
\hline Median (range) duration of asthma (years) & 16 & $(1-69)$ \\
\hline \multicolumn{3}{|l|}{ Smoking history } \\
\hline Past & 62 & $(45 \%)$ \\
\hline Present & 8 & $(6 \%)$ \\
\hline Never & 69 & $(49 \%)$ \\
\hline Current eczema $(n=130)$ & 39 & $(30 \%)$ \\
\hline Current hay fever $(\mathrm{n}=127)$ & 81 & $(64 \%)$ \\
\hline $\begin{array}{l}\text { Hospital admission for asthma } \\
\text { (in past } 12 \text { months) }\end{array}$ & 13 & $(9 \%)$ \\
\hline Mean (range) bronchodilator use (puffs per day) & \multicolumn{2}{|c|}{$3.4(0-19)$} \\
\hline Median (range) inhaled steroid dose ( $\mu \mathrm{g} /$ day) & 600 & $(150-3000)$ \\
\hline \multicolumn{3}{|l|}{ Skin prick test $(n=132)$} \\
\hline Atopic* & 79 & $(60 \%)$ \\
\hline $\operatorname{Der} p \mathrm{I}$ & 67 & \\
\hline $\operatorname{Derf} \mathrm{I}$ & 32 & \\
\hline Timothy grass & 56 & \\
\hline Cladosporium & 11 & \\
\hline Alternaria & 17 & \\
\hline Mean (SD) morning PEFR $(1 / \mathrm{min}) \dagger$ & 376 & $(115.03)$ \\
\hline Mean (SD) PEFR variability $(\%)^{* *}$ & 8.6 & $(7.9)$ \\
\hline Mean (SD) symptom scores $(0-3) * * *$ & 0.6 & $(0.52)$ \\
\hline
\end{tabular}

* Defined as at least one skin prick test positive ( $>3 \mathrm{~mm}$ weal).

** Peak flow variability computed $\frac{\mathrm{max}-\mathrm{min}}{\text { mean of am }+\mathrm{pm}} \times 100$

*** Symptom scores reported on a four point scale.

t Mean is the average of individual averages over 12 month period.

clusion were: diagnosis of COPD (8), living outside area (7), occupational asthma (1), and unwilling to participate in such a long study (50). The mean age of the subjects was 49 years and $66 \%$ were female. A total of 32493 person days of asthma symptom data were collected (median 279, range 29-351 days/ person). Summary baseline data concerning the main outcome variables (PEFR, PEFR variability, symptom scores) are presented in table 1 .

WEATHER

The weather in New Zealand during the study period was dominated by a cycle called "el Nino" with cooler, wetter weather throughout. Details of temperature, rainfall, and relative humidity over the study period are shown in table 2 . The mean daytime temperature during winter was $11.4^{\circ} \mathrm{C}$ and $23.5^{\circ} \mathrm{C}$ during summer. Rainfall was low overall but higher in the autumn and winter months, as expected. There were 244 days without rain. The maximum fall in barometric pressure in any two hour period was 4.7 mbar.

Weather and PEFR

Of the weather variables temperature, relative humidity, and maximum two hour fall in barometric pressure had a statistically significant
Table 3 Effect of $2 S D$ change in climate variables on peak expiratory flow rate (PEFR) the following morning $\begin{array}{ll}\text { Climate variable } & \begin{array}{l}\text { Mean \% change } \\ \text { in PEFR }\end{array}\end{array}$

\begin{tabular}{lrr}
\hline Mean temperature & 0.78 & 0.44 to 1.11 \\
Mean rainfall & -0.12 & -0.27 to 0.03
\end{tabular}
$\begin{array}{lrl}\text { Mean rainfall } & -0.12 & -0.27 \text { to } 0.03 \\ \text { Mean barometric pressure } & 0.11 & -0.05 \text { to } 0.27\end{array}$ Maximum two hour fall in pressure $-0.15 \quad-0.28$ to -0.02 Mean humidity 0.07 to 0.41

† Mean percentage change for a $2 \mathrm{SD}$ increase in the climate variable, adjusted for the effects of the other variables listed, spore and pollen levels and for linear and quadratic time effects. spo standard deviations were: temperature $4.4^{\circ} \mathrm{C}$, rainfall $0.38 \mathrm{~mm}$, barometric pressure $8.9 \mathrm{mbar}$ maximum pressure fall 0.78 mbar, relative humidity $9.9 \%$.

effect on PEFR the following morning (table 3). The absolute magnitude of these effects was very small. An increase in mean temperature of $2 \mathrm{SD}\left(8.8^{\circ} \mathrm{C}\right)$ was associated with a mean increase in PEFR of $3.01 / \mathrm{min}$. An increase in relative humidity of 2 SD $(19.8 \%)$ would cause a mean increase in PEFR of $1.01 / \mathrm{min}$. The associations seen with temperature and humidity remained statistically significant after controlling for use of reliever medication. Analysis of the relationship between weather during the day and PEFR in the evening of the same day showed a similar effect, with only temperature and barometric pressure showing a significant relationship with PEFR. Relative humidity and change in barometric pressure did not show an effect. The effect of weather on morning PEFR two days later (two day lag effect) appeared weaker. Analysis of the effects of seven day rolling means of climatic variables on morning PEFR also showed a small but statistically significant effect of temperature, but not relative humidity. An increase of $2 \mathrm{SD}$ in seven day average temperature $\left(7.6^{\circ} \mathrm{C}\right)$ was associated with a mean increase in PEFR of $0.87 \%$ or approximately $3.5 \mathrm{l} / \mathrm{min}$.

\section{Weather and asthma symptoms}

None of the climatic variables showed a relationship with worsening asthma symptoms as defined by a high score (table 4). A small association between rainfall and nocturnal wakening was seen. The relative risk of a change in night wakening was 1.22 for a 2SD change in rainfall (95\% CI 1.08 to 1.37). None of the climatic variables showed any relationship with an increased relative risk of high medication use.

POLLEN AND FUNGAL SPORES

Total pollen counts for the study period are shown in table 2 . There were typical seasonal

Table 2 Percentile points and means of the distributions for the climate and aeroallergen variables

\begin{tabular}{lrrrrrrr}
\hline & $10 \%$ & \multicolumn{1}{c}{$25 \%$} & \multicolumn{1}{c}{$50 \%$} & $75 \%$ & \multicolumn{1}{c}{$90 \%$} & Mean & $\%$ missing \\
\hline Average temperature $\left({ }^{\circ} \mathrm{C}\right)$ & 7.1 & 9.2 & 12.1 & 15.5 & 19.0 & 12.5 & 0.27 \\
Average barometric pressure (mbar) & 999.7 & 1006.1 & 1012.2 & 1017.6 & 1022.8 & 1011.4 & 6.03 \\
Average rainfall $(\mathrm{mm})$ & 0 & 0 & 0 & 0.04 & 0.38 & 0.13 & 0.27 \\
Average relative humidity (\%) & 67.5 & 73.0 & 80.5 & 86.3 & 92.1 & 79.8 & 0.27 \\
Total pollen $\left(\right.$ grains $\left./ \mathrm{m}^{3}\right)$ & 2.0 & 3.5 & 8.8 & 17.6 & 33.0 & 13.5 & 2.47 \\
Ascospores $\left(\times 10^{3} / \mathrm{m}^{3}\right)$ & 335.4 & 790.6 & 1713.0 & 3689.6 & 6313.0 & 2711.0 & 4.11 \\
Basidiospores $\left(\times 10^{3} / \mathrm{m}^{3}\right)$ & 86.7 & 195.0 & 522.4 & 1725.0 & 4492.2 & 1542.7 & 4.11 \\
Conidia $\left(\times 10^{3} / \mathrm{m}^{3}\right)$ & 1035.4 & 1451.7 & 2216.1 & 3856.7 & 5618.2 & 2898.0 & 4.11 \\
\hline
\end{tabular}


Table 4 Effect of climate variables on rate of occurrence of asthma symptoms (relative risk with $95 \%$ CI) $\dagger$

\begin{tabular}{llll}
\hline Climate variable & $\begin{array}{l}\text { High symptom } \\
\text { score days* }\end{array}$ & Waking at night & $\begin{array}{l}\text { High medication } \\
\text { use } \ddagger\end{array}$ \\
\hline Mean temperature & $1.03(0.88$ to 1.22$)$ & $1.16(0.84$ to 1.60$)$ & $0.97(0.77$ to 1.23$)$ \\
Mean rainfall & $1.11(0.91$ to 1.34$)$ & $1.22(1.08$ to 1.37$)$ & $1.21(0.98$ to 1.48$)$ \\
Mean barometric pressure & $1.05(0.95$ to 1.17$)$ & $0.95(0.85$ to 1.06$)$ & $1.03(0.92$ to 1.16$)$ \\
$\begin{array}{l}\text { Maximum two hour fall } \\
\text { in pressure }\end{array}$ & $1.10(0.99$ to 1.22$)$ & $0.93(0.83$ to 1.04$)$ & $0.92(0.82$ to 1.03$)$ \\
Mean relative humidity & $0.98(0.84$ to 1.13$)$ & $0.94(0.82$ to 1.26$)$ & $1.03(0.87$ to 1.21$)$ \\
\hline
\end{tabular}

* For each study participant a high symptom score day was defined as one on which the symptom score was at least one greater than the individual's modal score.

† Relative risk for a $2 S D$ increase in the climate variable, adjusted for the effects of the other variables listed, spore and pollen levels and for linear and quadratic time effects. The standard deviations were: temperature $4.4^{\circ} \mathrm{C}$, rainfall $0.38 \mathrm{~mm}$, barometric pressure 8.9 mbar, maximum two hour fall in pressure $0.78 \mathrm{mbar}$, relative humidity $9.9 \%$.

two hour fall in pressure $0.78 \mathrm{mbar}$, relative humidity $9.9 \%$.
$\ddagger$ For each study participant a high medication day was defined as one on which reliever

$\ddagger$ For each study participant a high medication day was defined as one on which reliever
medication was used at least two actuations more often than the individual's median level of use.

Table 5 Effect of spore and pollen levels on rate of occurrence of asthma symptoms (relative risk with $95 \% \mathrm{CI}) \dagger$

\begin{tabular}{|c|c|c|c|}
\hline Aeroallergen & High symptom score days* & Waking at night & High medication use $\ddagger$ \\
\hline \multicolumn{4}{|l|}{ Ascospores } \\
\hline Moderate v. low & $1.00(0.87$ to 1.16$)$ & $1.02(0.82$ to 1.26$)$ & $0.90(0.78$ to 1.04$)$ \\
\hline High v. low & $0.98(0.82$ to 1.19$)$ & $0.93(0.73$ to 1.19$)$ & $1.01(0.82$ to 1.24$)$ \\
\hline \multicolumn{4}{|l|}{ Basidiospores } \\
\hline Moderate v. low & 0.99 (0.86 to 1.15$)$ & $1.14(0.93$ to 1.40$)$ & $1.16(1.00$ to 1.35$)$ \\
\hline High v. low & $1.19(0.97$ to 1.46$)$ & $1.25(1.00$ to 1.56$)$ & $1.24(1.00$ to 1.53$)$ \\
\hline \multicolumn{4}{|l|}{ Conidia } \\
\hline Moderate v. lc & $0.94(0.84$ to 1.06$)$ & 1.03 (0.90 to 1.18$)$ & $1.04(0.91$ to 1.18$)$ \\
\hline High v. low & $0.84(0.72$ to 0.98$)$ & $0.99(0.81$ to 1.21$)$ & $0.94(0.81$ to 1.09$)$ \\
\hline \multicolumn{4}{|l|}{ Total pollen } \\
\hline Moderate v. low & $0.93(0.83$ to 1.04$)$ & $0.92(0.80$ to 1.05$)$ & $1.00(0.88$ to 1.13$)$ \\
\hline
\end{tabular}

* For each study participant a high symptom score day was defined as one on which the symptom score was at least one greater than the individual's modal score.

t Adjusted for the effects of the other variables listed, climatic variables and for linear and quadratic time effects.

$\ddagger$ For each study participant a high medication day was defined as one on which reliever medication was used at least two times more often than the individual's median level of use.

$\$$ There were no high total pollen days recorded during the study period.

trends in the distribution of counts during the 12 month study period with total pollen levels increasing during August and peaking in December and January. The overall pollen load is indicative of a low to moderate severity pollen season by New Zealand standards. Pine pollen counts showed a narrow season, peaking in September, while grass had a broader season between November and April.

The distribution of fungal spore counts for ascospores, basidiospores, and conidia during the study period is shown in table 2 . Ascospores showed peaks in late spring and autumn, basidiospores showed similar peaks but were more pronounced in autumn, while conidia had a sustained level throughout the year.

\section{Aeroallergens and PEFR}

There was no major influence of the levels of pollen and fungal spores on PEFR the following morning. After adjustment for temporal trend, climate, and fungal spores, PEFR increased following days of moderate pollen counts compared with days with low pollen counts (no days of high pollen counts were recorded). The mean change in PEFR between a low and a moderate pollen count day was $0.18 \%$ or $0.8 \mathrm{l} /$ min. This relationship remained after controlling for reliever medication use. Levels of fungal spores showed no association with PEFR the following morning. There was no association between levels of pollen or fungal spores and PEFR two days later (two day lag effect). There was also no relationship between PEFR and seven day rolling means of the aeroallergen variables.

\section{Aeroallergens and asthma symptoms}

Of all the pollen and spore categories, only basidiospores were significantly associated with worsening asthma (table 5). A day with high basidiospore levels was associated with a relative risk of 1.19 of a high symptom score day (95\% CI 0.97 to 1.46 ). Days with high basidiospore counts were also significantly associated with an increased risk of waking at night. High and moderately high basidiospore days were also associated with increased risk of high medication use. Paradoxically, a day with high conidia levels was associated with a relative risk of 0.84 ( 0.72 to 0.98$)$ of a high symptom score day - that is, the risk of high symptom scores decreased with high conidia levels.

\section{TIME VARIABLES}

After adjusting for climate, aeroallergens, and the quadratic time variable (indicative of a seasonal effect), the linear time effect was equivalent to an increase in morning PEFR of $2.8 \%$ (95\% CI $0.36 \%$ to $5.3 \%$ ) and an increase in evening PEFR of $1.02 \%$ (95\% CI $0.06 \%$ to $1.93 \%$ ) between the start and the finish of the study period. The estimates for the quadratic time variable suggested that, after controlling for climate, aeroallergens, and the linear time effect, mean morning PEFR was $1.9 \%$ lower in mid-winter compared with mid-summer $(95 \%$ CI $0.27 \%$ to $3.5 \%$ ).

\section{EXACERBATIONS}

A total of 54 exacerbations requiring nebuliser treatment were recorded during the year. There were no significant clusters of exacerbations. This number was inadequate to perform statistical analysis with respect to the effects of weather variables or aeroallergen levels.

\section{HETEROGENEITY}

There was little evidence of heterogeneity between individuals in the PEFR analyses or between groups in the analyses of symptom scores, nocturnal wakening, and use of reliever medication. In each case, and for each of the predictor variables, the estimated differences between groups or between individual variances was close to zero and substantially less than twice its standard error.

\section{Discussion}

This study has demonstrated a small but consistent positive association between temperature and PEFR, which would probably have little day to day significance in terms of exacerbations but might account for slightly higher PEFR during the summer months. There was also an association between days 
with high basidiospore counts and nocturnal wakening and reliever medication use.

We believe that this is the largest prospective study reported examining the effects of weather and aeroallergen levels on lung function and asthma symptoms. The size and power of the study are such that some associations have been observed which reach statistical significance, but which may not be clinically relevant, either due to their small absolute magnitude or the apparent implausibility of the relationship observed. Given that the study had $95 \%$ power to detect a 5\% change in PEFR associated with a $2 \mathrm{SD}$ change in climate variables, we believe that a type II error is unlikely to have occurred.

Previous investigators have studied asthma admissions to hospital or attendances at the emergency department and have related these to changes in weather or levels of aeroallergens. The prospective studies which have been reported have provided conflicting data, with associations reported between asthma admissions and weather variables (rainfall, ${ }^{4}$ barometric pressure, ${ }^{34}$ temperature, ${ }^{333}$ and humidity ${ }^{34}$ ) and aeroallergens (Ambrosia, ${ }^{35}$ basidiospores, ${ }^{45}$ uncategorised fungal spores, ${ }^{3}$ and algae ${ }^{4}$.

The results of our study suggest that the effects of weather and aeroallergen levels on PEFR and asthma symptoms on a day by day basis are small. Of the weather variables, only the previous day's temperature, relative humidity, and fall in barometric pressure had a statistically significant association with PEFR. The mean change in PEFR for an $8.8^{\circ} \mathrm{C}$ change in temperature (2SD) was $0.78 \%$ or approximately $3.0 \mathrm{l} / \mathrm{min}$. Rainfall had a small association with nocturnal wakening, with days of high rainfall being associated with an increased risk of waking at night with asthma.

The effects of changes in aeroallergen levels were also small. Days with high basidiospore levels were associated with increased nocturnal wakening and reliever medication use, and this association was supported by a modest but not significant effect on high symptom score days. There appeared to be no biologically plausible relationship between any other aeroallergen measured and asthma symptoms.

A number of factors may have contributed to the results observed. The weather during the study was unusual for the region in that it was cool but not particularly wet. There were no major thunderstorms or changes in barometric pressure. These have been identified in previous reports as being associated with epidemics of asthma admissions and it may be that these more dramatic climate events are necessary to release sufficient quantities of respirable allergens. ${ }^{7-9}$ The pollen profile was characteristic of seasonal trends observed in other studies in New Zealand and (by season but not calendar month) for northern hemisphere temperate zone studies. The total pollen load was indicative of a low to moderate pollen season.

We assumed for the purposes of this study that air pollution would be an unlikely phenomenon in this rural area. However, we recognise that particulate pollution and ground level ozone could both contribute to respiratory morbidity in such a geographical location and future studies would need to examine these factors.

The population studied was self-selected and represented approximately $10 \%$ of the likely adult asthmatic population of Blenheim. Seventy five percent of the subjects were prescribed inhaled anti-inflammatory medications, usually inhaled corticosteroids. The use of inhaled corticosteroids in the New Zealand adult asthmatic population is approximately $60 \%$ (W Bennett, Pharmaceutical Management Agency Ltd, personal communication). Despite the high proportion of subjects taking inhaled antiinflammatory medication, there was evidence of significant asthma morbidity amongst the study population with use of inhaled $\beta$ agonists averaging 3.4 doses per day and a total of 54 severe exacerbations during the study period. It is possible that reduced bronchial hyperresponsiveness provides an explanation for our failure to demonstrate a major role for inhaled pollens and fungal allergens.

Although only one spore trap was used for collection of spore and pollen data, and weather variables were only measured at one site, we do not consider that this is likely to have confounded the results. Most of the cohort lived within $19 \mathrm{~km}$ of the spore trap. Blenheim is a small town on flat land with few areas which might provide a microclimate. Previous studies have relied on data collected from a much larger geographical area.

Our data suggest that, in this population of subjects with asthma, on a day to day basis, there is little or no effect of weather and aeroallergen levels on PEFR or asthma symptoms. We have noted small effects of temperature, rainfall, humidity, and basidiospore levels which are generally in accord with other studies. ${ }^{343-36}$ We are unable to assess from this study whether exceptional days, such as days with massive fungal spore counts, might lead to exacerbations in a small subpopulation of asthmatic subjects, as is suggested by the data from emergency departments in cities with large populations. There were, however, no clusters of severe exacerbations to point towards exceptional days.

In conclusion, we believe that causes other than weather and airborne pollen and spore levels have to be found to explain day to day variation in asthma symptoms and PEFR in the general population. Possible contributing factors include viral respiratory tract infections ${ }^{37}$ or increased bronchial responsiveness due to inadequate compliance with inhaled corticosteroid medication.

The authors wish to thank The Health Research Council of New Zealand and The Marlborough Express for funding for this study, and Dr M Leonard and support staff at Waira Hospital, Blenheim. The assistance of Dr Izabella KonzakIslam with pollen counting is gratefully acknowledged. Mr P Islam with pollen counting is gratefully acknowledged. Mr P Graham was funded by the Health Research Council of New Zealand. Thanks also to Kathy Withell and Sally Bagley for

1 Bellomo R, Gigliotti P, Treloar A, Holmes P, Suphioglu C, Singh $\mathrm{MB}$, et al. Two consecutive thunderstorm associated epidemics of asthma in the city of Melbourne. The possible role of rye grass pollen. Med F Aust 1992;156:834-7. 
2 Carey MJ, Cordon I. Asthma and climatic conditions: experience from Bermuda, an isolated island community. BMF 1986;293:843-4.

3 Hobday JD, Stewart AJ. The relationship between daily asthma attendance, weather parameters, spore count and pollen count. Aust NZ F Med 1973;3:552-6.

4 Khot A, Burn R, Evans N, Lenney W, Storr J. Biometeorological triggers in childhood asthma. Clin Allergy 1988;18:351-8.

5 Subiza J, Cabrera M, Valdivieso R, Subiza J-L, Jerez M, Jimenez JA, et al. Seasonal asthma caused by airborne Platanus pollen. Clin Exp Allergy 1994;24:1123-9.

6 Packe GE, Ayres JG. Asthma outbreak during a thunderstorm. Lancet 1985:199-204.

7 Bauman A. Asthma associated with thunderstorms. BMF 1996;312:590-1.

8 Davidson AC, Emberlin J, Cook AD, Venables KM. A major outbreak of asthma associated with a thunderstorm: experience of accident and emergency departments and patients' characteristics. BMF 1996:312:601-4.

9 Celenza A, Fothergill J, Kupek E, Shaw RJ. Thunderstorm associated asthma: a detailed analysis of environmental factors. BMF 1996;312:604-7

10 Anto JM, Sunyer J, Rodriguez-Roisin R, Suarez-Cervera M, Vazquez L. Community outbreaks of asthma associated with inhalation of soybean dust. N Engl F Med 1989;320: 1097-102.

11 Knox RB. Pollen and allergy. London: Edward Arnold, 1979: 43-51.

12 Solomon WR. Aerobiology of pollinosis. F Allergy Clin Immunol 1984;74:449-61.

13 Pollart SM, Reid MJ, Fling JA, Chapman MD, PlattsMills TAE. Epidemiology of emergency room asthma in Mills TAE. Epidemiology of emergency room asthma in Northern California: association with IgE antibody to

14 Oei HD, Spieksma FTM, Bruynzeel PLB. Birch pollen asthma in the Netherlands. Allergy 1986;41:435-41.

15 Boulet L-P, Cartier A, Thomson NC, Roberts RS, Dolovich J, Hargreave FE. Asthma and increases in nonallergic bronchial responsiveness from seasonal pollen exposure. f Allergy Clin Immunol 1983;71:399-406.

16 Löwhagan O, Rak S. Modification of bronchial hyperreactivity after treatment with sodium cromoglycate during pollen season. F Allergy Clin Immunol 1985;75:460-7.

17 Sotomayor H, Badier M, Vervloet D, Orehek J. Seasonal increase of carbachol airway responsiveness in patients allergic to grass pollen. Am Rev Respir Dis 1984;130:56-8.

18 Targonski PV, Persky VW, Ramekrishnan V. Effect of environmental molds on risk of death from asthma during
the pollen season. F Allergy Clin Immunol 1995;95:955-61.

19 Hasnain SM, Wilson JD, Newhook FJ. Fungi and disease. Fungal allergy and respiratory disease. NZ Med 71985 ; 98:342-6.
20 Klabuschnigg A, Gotz M, Horak F, Jager S, Machalek A, Popow C, et al. Influence of aerobiology and weather on symptoms in children with asthma. Respiration 1981;42 $52-60$.

21 Forsberg B, Stjernberg N, Falk M, Lundbäck B, Wall S. Air pollution levels, meteorological conditions and asthma symptoms. Eur Respir F 1993;6:1109-15.

22 American Thoracic Society. Standards for the diagnosis and care of patients with chronic obstructive pulmonary disease (COPD) and asthma. Am Rev Respir Dis 1987;136:225-44.

23 Ware JH. Linear models for the analysis of longitudinal studies. Am Stat 1985;39:95-101.

24 Diem JE, Liukkonen JR. A comparative study of three methods for analysing longitudinal pulmonary function data. Stat Med 1988;7:19-28.

25 Korn EL, Whittemore AS. Methods for analyzing panel studies of acute health effects of air pollution. Biometrics studies of acute heal

26 Ostrom CW. Time series analysis: regression techniques. Sage University paper series on quantitative applications in the social sciences, 07-009. Beverly Hills and London. Sage Publications, 1978

27 Dempster AP, Ryan LM. Weighted normal plots. F Am Stat Assoc 1985;80:845-50.

28 Gourieroux C, Monfort A, Trognon A. Pseudo-maximum likelihoods methods: theory. Econometrica 1984;52:681700

29 Royall RM. Model robust confidence intervals using maximum likelihood estimates. Int Statist Rev 1986;54:221-6.

30 SAS Institute Inc. SAS/STAT user's guide. Release 6.03. Cary, North Carolina: SAS Institute Inc, 1988.

31 SAS Institute Inc. SAS technical report P-200, SAS/STAT Software: CALIS and LOGISTIC procedures. Release 6.04. Cary, North Carolina: SAS Institute Inc, 1990.

32 Aptech Systems Inc. The Gauss system version 3.1. Maple Aptech Systems Inc. The Gauss system version 3.1

33 Rossi OVJ, Kinnula VL, Tienari J, Huhti E. Association of severe asthma attacks with weather, pollen and air pollutants. Thorax 1993;48:244-8.

34 Salvaggio J, Hasselblad V, Seabury J, Heiderscheit LT New Orleans asthma. II. Relationship of climatologic and seasonal factors to outbreaks. F Allergy 1970;45:257-65.

35 Salvaggio J, Seabury J, Schoenhardt EA. New Orlean asthma. V. Relationship between Charity Hospital asthma admission rates, semiquantitative pollen and fungal spore counts, and total particulate aerometric sampling data. $\mathcal{F}$ Allergy Clin Immunol 1971;48:96-114.

36 Beer SI, Kannai YI, Waron MJ. Acute exacerbation of bronchial asthma in children associated with afternoon weather changes. Am Rev Respir Dis 1991;144:31-5.

37 Bardin P, Johnston SL, Pattemore PK. Viruses as precipitants of asthma symptoms. II. Physiology and mechanisms. Clin Exp Allergy 1992;22:809-22. 